\title{
First-in-human phase I clinical trial of RG7356, an anti- CD44 humanized antibody, in patients with advanced, CD44- expressing solid tumors
}

\author{
C. Willemien Menke-van der Houven van Oordt ${ }^{1}$, Carlos Gomez-Roca ${ }^{2}$, Carla van \\ Herpen $^{3}$, Andrew L. Coveler ${ }^{4}$, Devalingam Mahalingam ${ }^{5}$, Henk M. W. Verheul ${ }^{1}$, \\ Winette T. A. van der Graaf ${ }^{3}$, Randolph Christen ${ }^{6}$, Dominik Rüttinger ${ }^{7}$, Stefan \\ Weigand7, Michael A. Cannarile7, Florian Heil', Michael Brewster ${ }^{8}$, Antje-Christine

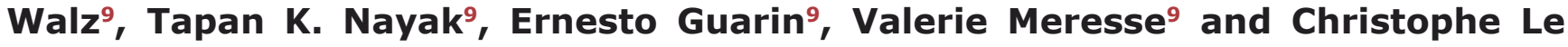 \\ Tourneau ${ }^{10}$ \\ ${ }^{1}$ Department of Medical Oncology, VU University Medical Center, Amsterdam, The Netherlands \\ ${ }^{2}$ Clinical Research Unit, Department of Medical Oncology, Institut Claudius Regaud, Institut Universitaire du Cancer de \\ Toulouse - Oncopole, Toulouse, France \\ ${ }^{3}$ Radboud University Medical Center, Nijmegen, The Netherlands \\ ${ }^{4}$ Department of Medicine, Division of Oncology, University of Washington, Seattle, WA, USA \\ ${ }^{5}$ Cancer Therapy and Research Center, University of Texas Health Science Center, San Antonio, TX, USA \\ ${ }^{6}$ Product Development, Safety Risk Management, Roche, Basel, Switzerland \\ 7 Pharma Research \& Early Development, Roche Innovation Center, Penzberg, Germany \\ ${ }^{8}$ Pharma Research \& Early Development, Roche Innovation Centre, Welwyn, UK \\ ${ }^{9}$ Pharma Research \& Early Development, Roche Innovation Center Basel, Basel, Switzerland \\ 10 Department of Medical Oncology, Institut Curie, Saint-Cloud \& Paris, France, and Versailles-Saint-Quentin-en-Yvelines \\ University, Versailles, France \\ Correspondence to: C. Willemien Menke-van der Houven van Oordt, email: c.menke@vumc.nl \\ Keywords: RG7356, anti-CD44 humanized antibody, advanced solid tumors, advanced CD44-expressing solid malignancies, \\ phase I trial \\ Received: March 28, $2016 \quad$ Accepted: July 10, $2016 \quad$ Published: August 05, 2016
}

ABSTRACT

Transmembrane glycoprotein CD44 is overexpressed in various malignancies. Interactions between CD44 and hyaluronic acid are associated with poor prognosis, making CD44 an attractive therapeutic target. We report results from a first-in-human phase I trial of RG7356, a recombinant anti-CD44 immunoglobulin G1 humanized monoclonal antibody, in patients with advanced CD44-expressing solid malignancies.

Sixty-five heavily pretreated patients not amenable to standard therapy were enrolled and received RG7356 intravenously biweekly (q2w) or weekly (qw) in escalating doses from $100 \mathrm{mg}$ to $2,250 \mathrm{mg}$. RG7356 was well tolerated. Most frequent adverse events were fever, headache and fatigue. Dose-limiting toxicities included headache $(1,500 \mathrm{mg} \mathrm{q} 2 \mathrm{w}$ and $1,350 \mathrm{mg} \mathrm{qw})$ and febrile neutropenia (2,250 $\mathrm{mg} \mathrm{q2w})$. The maximum tolerated dose with $q 2 \mathrm{w}$ dosing was $1,500 \mathrm{mg}$, but was not defined for qw dosing due to early study termination. Clinical efficacy was modest; 13/61 patients $(21 \%)$ experienced disease stabilization lasting a median of 12 (range, 6-35) weeks. No apparent dose- or dose schedule-dependent changes in biological activity were reported from blood or tissue analyses. Tumor-targeting by positron emission tomography (PET) using ${ }^{89} \mathrm{Zr}$-labeled RG7356 was observed for doses $\geq 200 \mathrm{mg}$ (q2w) warranting further investigation of this agent in combination regimens. 


\section{INTRODUCTION}

CD44 is a single-chain, transmembrane glycoprotein involved in cell-cell and cell-matrix interactions [1]. Interaction between CD44 and its main ligand, hyaluronic acid (HA), may be important in tumor growth and treatment resistance via cell proliferation, differentiation, and migration [1]. These interactions further influence interstitial fluid pressure, tumor-associated macrophage attraction, and angiogenesis [1, 2]. CD44 encompasses a diverse family of molecules originating from alternative splicing and posttranslational modifications in different cells $[1,2]$. CD44 standard (CD44s) and variant (CD44v) isoforms are aberrantly expressed in various cancers [3] and their interaction with HA influences cell migration and homing [4]. CD44, also expressed on cancer stem cells (CSC) in various tumors, is associated with chemoresistance and tumor regrowth following standard therapy [5]. As CD44 overexpression is linked to tumor aggressiveness and metastatic potential in many tumors, it is an attractive therapeutic target $[1,3]$. The anti-CD44 antibody bivatuzumab, directed against the variable region CD44v6, has demonstrated clinical activity in phase I studies; however, lethal toxic epidermal necrolysis halted further development [6-8].

Investigational RG7356, a novel recombinant immunoglobulin G1 humanized monoclonal antibody $(\mathrm{mAb})$, selectively binds near the HA-binding region of the extracellular domain of all CD44 isoforms. Preclinical studies suggest that higher levels of HA and expression of $\mathrm{CD} 44 \mathrm{~s}$ versus $\mathrm{CD} 44 \mathrm{v}$ on cells are important for RG7356 activity [4]. RG7356 has also demonstrated growth inhibition of several CD44-expressing tumor xenografts (Roche internal data). Its mode of action has been postulated to include phagocytosis of CD44 positive cancer (stem) cells, which in preclinical studies has been suggested to involve $\mathrm{Fc}$-mediated activation of macrophages [4], as well as being involved in direct cell killing of CD44- positive cancer cells.

We report a first-in-human, multicenter, phase I clinical trial of RG7356 in patients with metastatic or locally advanced CD44-expressing solid malignancies not amenable to standard therapy. Biodistribution of RG7356 was evaluated using ${ }^{89} \mathrm{Zr}-\mathrm{RG} 7356$ positron emission tomography (PET).

\section{RESULTS}

\section{Patient characteristics}

Sixty-five patients were enrolled consecutively from June 2011 through November 2013. In Arm A, 40 patients received RG7356 biweekly ( $22 w)$ in 8 dose cohorts (100 to $2,250 \mathrm{mg}$ ), and 12 patients received the weekly (qw) regimen (675-mg and 1,350-mg cohorts). Thirteen patients in the substudy imaging group (Arm B) received $1 \mathrm{mg}$ ${ }^{89} \mathrm{Zr}$-RG7356 after 0-mg to 674-mg unlabeled RG7356 prior to PET imaging (Supplemental Material, online only). Patients received a median of 3.5 prior therapies in Arm A and 3.0 in Arm B (Table 1).

\section{Safety and tolerability}

Overall, 317 treatment-related adverse events (AEs), mostly mild to moderate, were reported in 61 patients, with comparable event rates in arms A and B (Table 2). Grade 3 and 4 AEs were reported in 25\% (16/65) and 5\% (3/65) of patients, respectively. Most common treatment-related AEs included headache $(38 / 65,58 \%)$ and pyrexia $(30 / 65$, $46 \%$ ). Infusion-related reactions (IRRs) did not appear to be dose schedule-dependent and were predominantly observed during the first infusion. Most IRRs were grade 1 or 2, well managed with recommended premedication, and resolved without clinical sequelae. Overall, 52 serious AEs were reported in 31 patients; 11 events (pyrexia, headache, abdominal pain, febrile neutropenia, and nausea) were considered study drug related.

Three dose-limiting toxicities (DLTs) included 2 cases of grade 3 headache (1,500 $\mathrm{mg} \mathrm{q} 2 \mathrm{w}, 1,350 \mathrm{mg} \mathrm{qw})$ and 1 grade 4 febrile neutropenia $(2,250 \mathrm{mg} \mathrm{q} 2 \mathrm{w})$. As the first DLT occurred with 1,500 mg q2w, this cohort was expanded to 6 patients; no additional DLT was observed. In the subsequent 2,250 mg q2w cohort, 1 DLT occurred in 3 evaluable patients. The safety study management team decided not to further expand this cohort, as drug exposure was judged insufficient owing to rapid antibody clearance. Instead more frequent (weekly) dosing was implemented to increase drug exposure.

The safety profile of the qw regimen was comparable with that for $\mathrm{q} 2 \mathrm{w}$ (Table 2). Lower rates of IRRs (58\%) compared with $\mathrm{q} 2 \mathrm{w}$ dosing coincided with the introduction of a slower infusion protocol. Thus, the maximum tolerated dose (MTD) for the $\mathrm{q} 2 \mathrm{~W}$ regimen was determined at 1,500 $\mathrm{mg}$ and was not reached in the qw regimen owing to study termination (sponsor decision) prior to any further dose escalation after the highest tested 1,350-mg dose.

In the $\mathrm{q} 2 \mathrm{w}$ cohort, interference with the Coombs test post infusion was observed. Subsequent analysis of the qw cohort showed that the indirect and direct Coombs test became positive after the first infusion in 57\% (4/7) and $55 \%(6 / 11)$ of patients, respectively, and became negative again in 2 (at 675 and $1,350 \mathrm{mg} \mathrm{qw}$ ) and 3 patients (at 675 , 1,350 , and $1,350 \mathrm{mg} \mathrm{qw}$ ), respectively, at the cycle 1 day 8 assessment (data not shown). No hemolysis was reported. A de-risking strategy was implemented (pre-dose Coombs testing on day 1 of cycles 1 and 8 and at end of treatment visit). No AEs due to this interference have been observed. 
Table 1: Patient characteristics.

\begin{tabular}{|c|c|c|c|}
\hline \multirow[b]{2}{*}{ Characteristic } & \multicolumn{2}{|c|}{$\operatorname{Arm~A}$} & \multirow{2}{*}{$\begin{array}{c}\text { Arm B } \\
q 2 w \\
N=13\end{array}$} \\
\hline & $\begin{array}{c}q 2 w \\
N=40\end{array}$ & $\begin{array}{c}\mathrm{qw} \\
N=12\end{array}$ & \\
\hline Median age (range), years & $65(41-80)$ & $57(25-65)$ & $61(40-79)$ \\
\hline Male, n (\%) & $22(55)$ & $5(42)$ & $10(77)$ \\
\hline \multicolumn{4}{|l|}{ Race, n (\%) } \\
\hline Asian & $2(5)$ & 0 & $1(8)$ \\
\hline Black/African American & $2(5)$ & $2(17)$ & 0 \\
\hline White & $35(88)$ & $10(83)$ & $12(92)$ \\
\hline Other & $1(3)$ & 0 & 0 \\
\hline \multicolumn{4}{|l|}{ ECOG, $n(\%)$} \\
\hline 0 & $11(28)$ & $5(42)$ & $2(15)$ \\
\hline 1 & $27(68)$ & $6(50)$ & $10(77)$ \\
\hline 2 & $2(5)$ & $1(8)$ & $1(8)$ \\
\hline \multicolumn{4}{|l|}{ Primary cancer, $n(\%)$} \\
\hline Colon/large intestine & $15(38)$ & 0 & $4(31)$ \\
\hline Rectum & $8(20)$ & 0 & $1(8)$ \\
\hline Breast & $2(5)$ & $3(25)$ & 0 \\
\hline Melanoma & $3(8)$ & $2(17)$ & $1(8)$ \\
\hline Head and neck & $2(5)$ & 0 & $2(15)$ \\
\hline Skin & $1(3)$ & $1(8)$ & 0 \\
\hline Soft tissue & $1(3)$ & $1(8)$ & 0 \\
\hline Uterus & $1(3)$ & $1(8)$ & 0 \\
\hline Cervix & $1(3)$ & 0 & $2(15)$ \\
\hline $\begin{array}{l}\text { Esophagus, gastric, } \\
\text { gastroesophageal junction }\end{array}$ & $3(7)$ & 0 & $1(8)$ \\
\hline Kidney & 0 & $1(8)$ & 0 \\
\hline Pancreas & 0 & $1(8)$ & 0 \\
\hline Thymus & $1(3)$ & 0 & 0 \\
\hline Other $^{\mathrm{a}}$ & $2(3)$ & $1(8)$ & $2(15)$ \\
\hline Median line of prior therapy (range) & $3.5(0-9)$ & $3.5(0-7)$ & $3.0(1-7)$ \\
\hline
\end{tabular}

Abbreviations: ECOG, Eastern Cooperative Oncology Group; qw, weekly; q2w, biweekly

a"Other" includes bone, adenoid cystic carcinoma of glandula submandibularis, cholangiocarcinoma, chondrocarcinoma, ear, nasopharynx, and eye.

Patient withdrawals were due to death $(n=1)$, withdrawal of consent $(n=3)$, and AEs $(n=6)$, which included 3 patients with DLTs. All other withdrawals were due to progressive disease $(n=55)$. None of the 24 deaths in the study were considered study drug related, as assessed by the investigator; all deaths were assessed by the investigators to be due to disease progression.

\section{Pharmacokinetic assessments}

In Arm A, the mean peak concentration and area under the curve (AUC) at RG7356 doses up to 2,250 $\mathrm{mg}$ showed nonlinear pharmacokinetics (PK). More than dose-proportional increases in drug exposure were observed at doses of 100-450 mg, with dose-proportional increases indicative of clearance being a dose-dependent and potentially saturable process that plateaus at higher doses (Figure 1A). Volume of distribution was high and apparent mean half-life of approximately 50-70 hours remained similar across doses. Doubling of exposure was achieved by changing from $\mathrm{q} 2 \mathrm{w}$ to qw dosing (Figure 1B).

\section{Antitumor activity}

Following treatment with RG7356, most patients progressed after cycle 2. Median time on treatment was 4 (range, 0.14-34) weeks. Of 61 evaluable patients, $21 \%$ $(13 / 61)$ had stable disease (SD) as best response (Figure 2); 3 patients with colorectal cancer and 1 patient each with thymus and skin cancer showed some tumor shrinkage, although not sufficient to qualify as an objective response according to RECIST criteria. Tissue analysis revealed no specific trend in immune cell infiltration or proliferation (data not shown). 


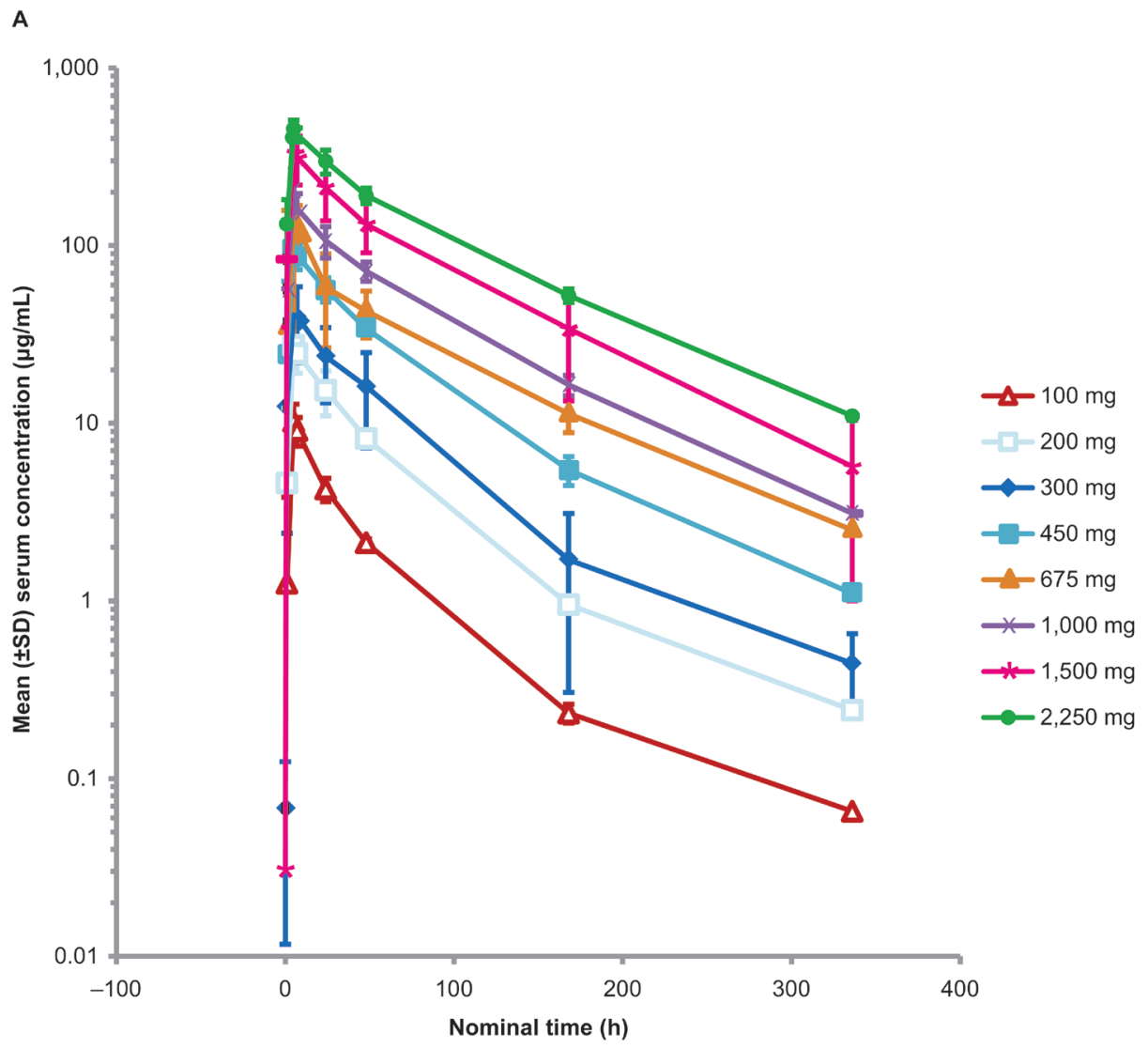

B

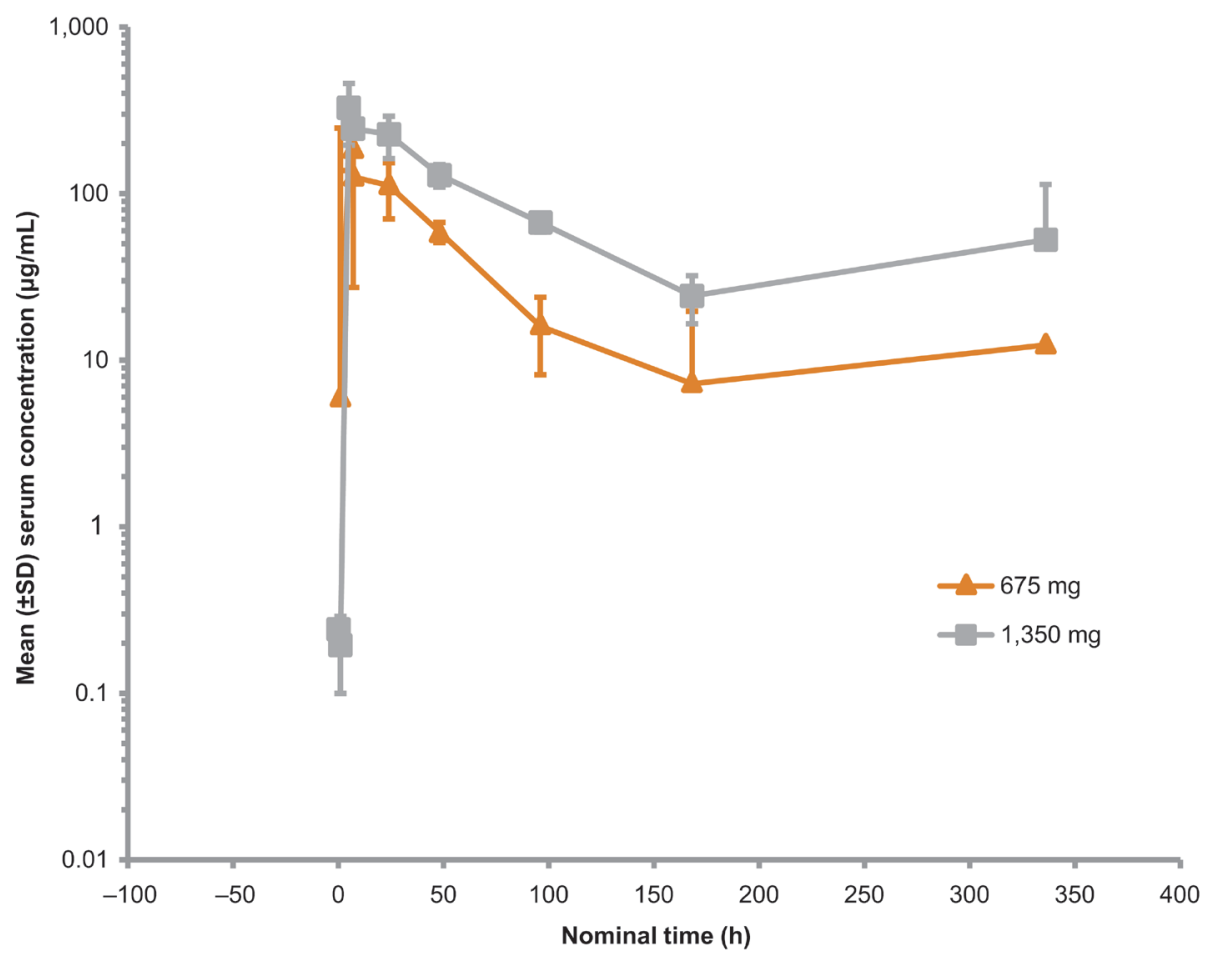

Figure 1: RG7356 serum concentration versus time plot in patients in Arm A who received the biweekly (q2w) (A) and weekly (qw) (B) dosing schedules. 
Table 2: Safety overview.

\begin{tabular}{|c|c|c|c|c|c|}
\hline \multirow[b]{2}{*}{ Category } & \multicolumn{2}{|c|}{$\operatorname{Arm~A~}$} & \multirow{2}{*}{$\begin{array}{c}\text { Arm B } \\
\mathbf{q W} \\
N=13\end{array}$} & \multirow{2}{*}{\multicolumn{2}{|c|}{$\begin{array}{c}\text { Total } \\
N=65\end{array}$}} \\
\hline & $\begin{array}{c}q 2 w \\
N=40\end{array}$ & $\begin{array}{l}\text { Weekly } \\
N=12\end{array}$ & & & \\
\hline Any $\mathrm{AE}, n(\%)$ & $40(100)$ & $12(100)$ & $13(100)$ & \multicolumn{2}{|c|}{$65(100)$} \\
\hline Total number of AEs & 378 & 128 & 113 & \multicolumn{2}{|c|}{619} \\
\hline Related AE, $n(\%)$ & $39(98)$ & $10(83)$ & $12(92)$ & \multicolumn{2}{|c|}{$61(94)$} \\
\hline Total number of related AEs & 218 & 57 & 42 & \multicolumn{2}{|c|}{317} \\
\hline Related grade $\geq 3 \mathrm{AE}, n(\%)$ & $12(30)$ & $3(25)$ & $2(15)$ & \multicolumn{2}{|c|}{$17(26)$} \\
\hline Total number of related grade $\geq 3$ AEs & 14 & 5 & 3 & \multicolumn{2}{|c|}{22} \\
\hline SAE, $n(\%)$ & $16(40)$ & $8(67)$ & $7(54)$ & \multicolumn{2}{|c|}{$31(48)$} \\
\hline Total number of SAEs & 24 & 14 & 14 & \multicolumn{2}{|c|}{52} \\
\hline Related SAE, $n(\%)$ & $5(12)$ & $1(8)$ & $3(23)$ & \multicolumn{2}{|c|}{$9(14)$} \\
\hline Total number of related SAEs & $5(12)$ & $1(8)$ & $5(38)$ & \multicolumn{2}{|c|}{$11(17)$} \\
\hline Infusion-related reactions, $n(\%)$ & $27(68)$ & $7(58)$ & $10(77)$ & \multicolumn{2}{|c|}{$44(68)$} \\
\hline $\begin{array}{c}\text { Total number of infusion-related reaction } \\
\text { events }\end{array}$ & 72 & 15 & 27 & \multicolumn{2}{|c|}{114} \\
\hline Serious infusion-related reactions $n(\%)$ & $2(5)$ & 0 & 0 & \multicolumn{2}{|c|}{$2(3)$} \\
\hline AE leading to withdrawal, $n(\%)$ & $2(5)$ & $2(17)$ & $2(15)$ & \multicolumn{2}{|c|}{$6(9)$} \\
\hline Deaths, $n(\%)$ & $16(40)$ & $2(17)$ & $6(46)$ & \multicolumn{2}{|c|}{$24(37)$} \\
\hline DLT $^{\mathrm{a}}$ & $2(5)$ & $1(8)$ & 0 & \multicolumn{2}{|c|}{$3(5)$} \\
\hline \multirow[b]{2}{*}{$\begin{array}{l}\text { Treatment-related }{ }^{\mathrm{b}} \text { AEs in } \\
\geq \mathbf{1 0 \%} \text { of patient population, } \\
\mathbf{n}(\%)^{\mathrm{c}}\end{array}$} & \multirow{2}{*}{\multicolumn{2}{|c|}{$39(75)$}} & \multirow[b]{2}{*}{$12(92)$} & \multicolumn{2}{|c|}{ Total } \\
\hline & & & & \multicolumn{2}{|c|}{$\begin{array}{c}\text { Proportion } \\
\text { of treatment- } \\
\text { related AEs } \\
\text { grade } \geq \mathbf{3}^{\mathbf{d}} \\
\end{array}$} \\
\hline Headache & $26(65)$ & $6(50)$ & $6(46)$ & $38(58)$ & $2(4)$ \\
\hline Asthenia/fatigue & $22(55)$ & $8(50)$ & 0 & $30(46)$ & $1(2)$ \\
\hline Pyrexia & $18(45)$ & $3(25)$ & $9(69)$ & $30(46)$ & $1(2)$ \\
\hline Chills & $10(25)$ & $1(8)$ & $4(31)$ & $15(23)$ & 0 \\
\hline Nausea & $8(20)$ & $2(17)$ & $5(38)$ & $15(23)$ & $1(2)$ \\
\hline Decreased appetite & $9(23)$ & $3(25)$ & $2(15)$ & $14(22)$ & $1(2)$ \\
\hline Vomiting & $6(15)$ & $3(25)$ & $3(23)$ & $12(18)$ & $1(2)$ \\
\hline Rash/maculopapular rash & $5(13)$ & $4(33)$ & 0 & $9(14)$ & 0 \\
\hline Diarrhea & $5(13)$ & $2(17)$ & $1(8)$ & $8(12)$ & 0 \\
\hline Conjunctivitis & $4(10)$ & $1(8)$ & $2(15)$ & $7(11)$ & 0 \\
\hline Dizziness & $7(18)$ & 0 & 0 & $7(11)$ & 0 \\
\hline
\end{tabular}

Abbreviations: AE, adverse event; DLT, dose-limiting toxicity; q2w, biweekly; qw, weekly; SAE, serious adverse event. Erythema and dry eye were reported as treatment-related AEs in $4(6 \%)$ and $3(5 \%)$ patients, respectively.

aDTs occurred in the 1,500 and 2,250 $\mathrm{mg}$ q2w cohorts and 1,350 $\mathrm{mg}$ qw cohort.

${ }^{\mathrm{b}}$ Investigator assessed.

${ }^{c}$ Calculated as proportion of total number of patients who experienced any AE in that treatment group.

${ }^{\mathrm{d}}$ Calculated as proportion of total number of patients who experienced any treatment-related AE.

\section{Biomarker analysis}

Analysis of peripheral blood cells showed a temporary dose- and dosing regimen-independent decrease of $\mathrm{CD}^{+} 4^{+}$monocytes after first infusion (Figure $3 \mathrm{~A})$. No trend for RG7356-induced CD68 $8^{+}$macrophage alteration was observed (Figure 3B). Additionally, no relevant changes in tumor proliferation [Ki67 immunohistochemistry (IHC)], CD44 expression (CD44
IHC), and CD44-mediated signaling (phosphorylated ERK IHC) was demonstrated in tumor tissue with RG7356 treatment (data not shown).

Cytokine release was temporary, peaking at 1.5 hours after the first infusion and returning towards baseline levels within 24 hours after infusion (Figure 3C-3F). Additionally, a secondary cytokine release was observed in some patients upon repeated RG7356 infusion with similar kinetics as the first infusion-related 
cytokine release. This secondary cytokine release was not correlated to AEs, DLTs, or other biomarkers measured. Overall, cytokine changes do not seem to be dependent on dose level or dose schedule (Figure 3C-3F).

We also investigated whether observed DLTs (Table 2) could be linked to cytokine release in the serum of RG7356-treated patients. The patient who experienced dose-limiting grade 3 febrile neutropenia on study day 18 (Patient 2010) showed the highest temporary increase of monocyte chemotactic protein 1 and inflammatory cytokine interleukin (IL)-8 after 1.5 hours post first infusion compared with remaining patients. However, the pattern of increase for IL-6 and IL-10 was similar compared with the other patients (Figure 3). At the time of the febrile neutropenia event, cytokine levels were not assessed. Two patients experienced dose-limiting headache. Overall, cytokine levels in these 2 patients were similar to those in other patients treated with RG7356.

\section{Imaging}

Early response evaluation with fluorodeoxyglucose (FDG)-PET showed a partial metabolic response according to European Organisation for Research and Treatment of Cancer criteria in $23.5 \%(8 / 34)$ of patients (119 tumor lesions). No correlation between changes in maximum standardized uptake value or metabolic tumor volume and dose exposition was found. Assessment of baseline and on-treatment vascular characteristics in 20 evaluable patients using dynamic contrast-enhanced magnetic resonance imaging (DCE-MRI) showed changes in initial AUC defined over the first 60 seconds postenhancement, reflecting a mixed pattern of increase and decrease in vascular characteristics and changes in fluid pressure (data not shown). No correlation with clinical efficacy was observed.

Immuno-PET analysis revealed that ${ }^{89} \mathrm{Zr}-\mathrm{RG} 7356$ localized to bone marrow, liver, and spleen. Tumor targeting was detected with coadministration of $\geq 199$ mg unlabeled antibody in 7/10 patients (Figure 4). Most lesions seen with FDG-PET also could be detected with ${ }^{89} \mathrm{Zr}-\mathrm{RG} 7356$ (23/28 lesions; data not shown).

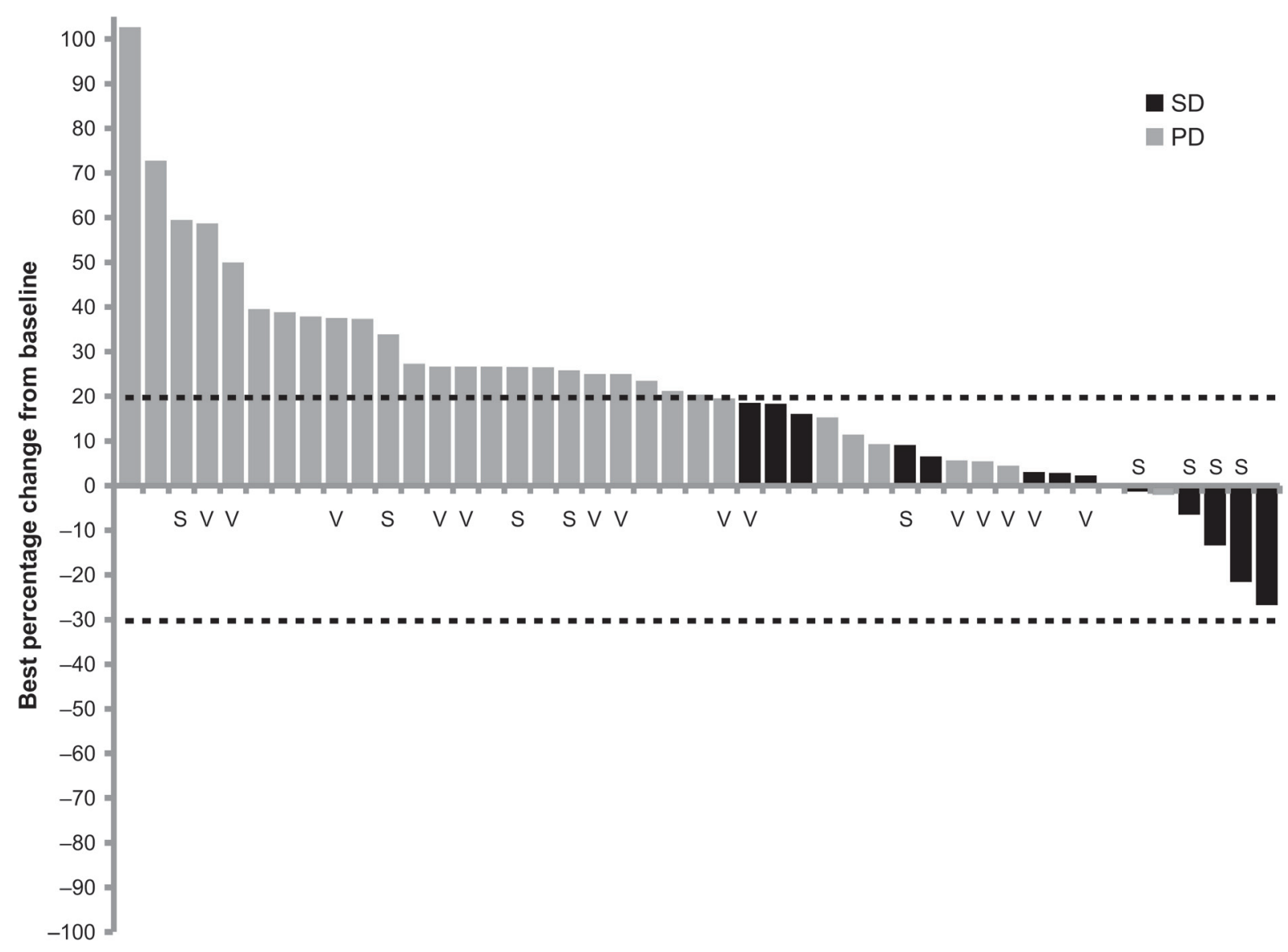

Figure 2: Waterfall plot showing best response of individual patients according to RECIST criteria. 45 patients had tumor lesion evaluation during the study. Abbreviations: PD (progressive disease); SD (stable disease). 
A

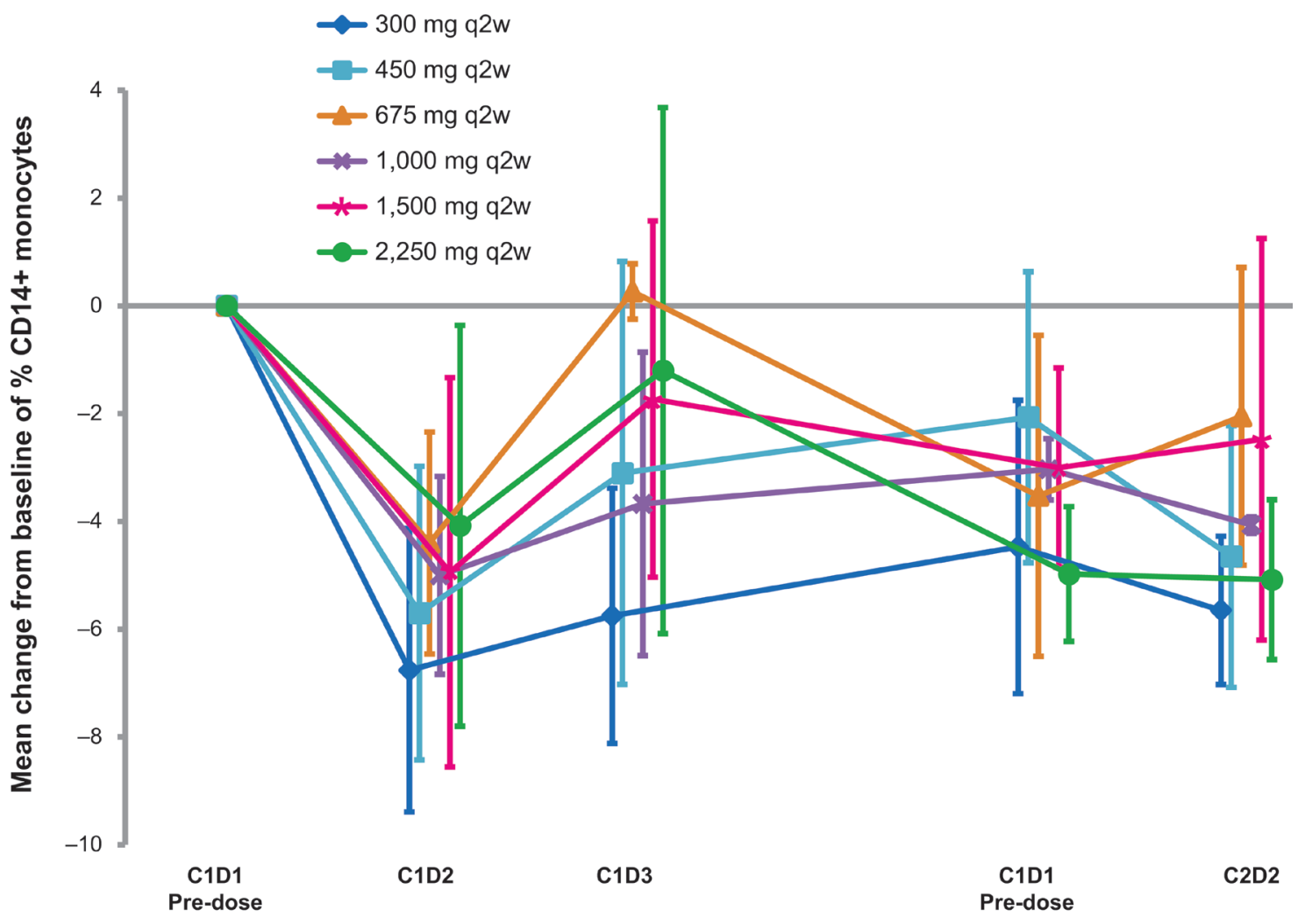

B

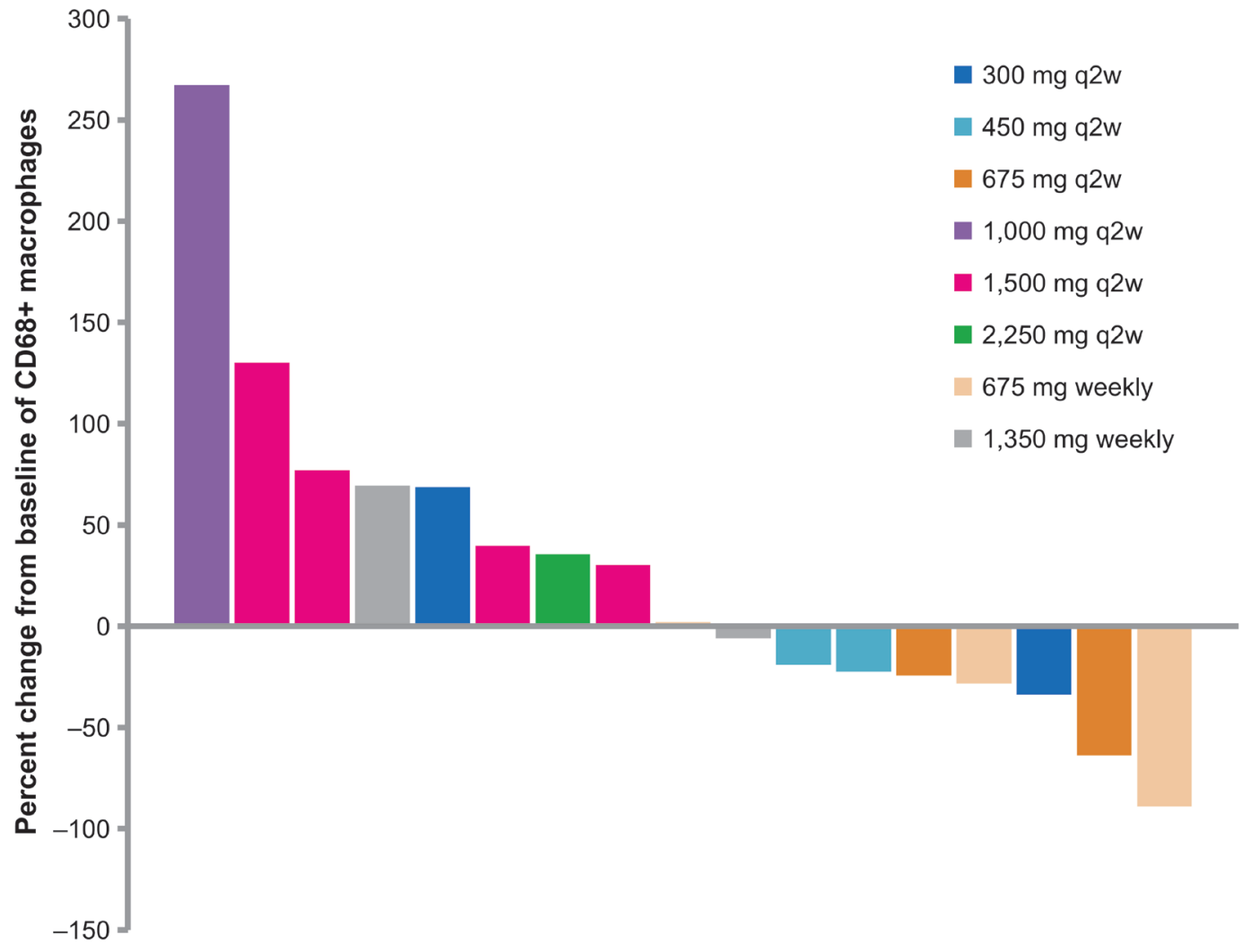




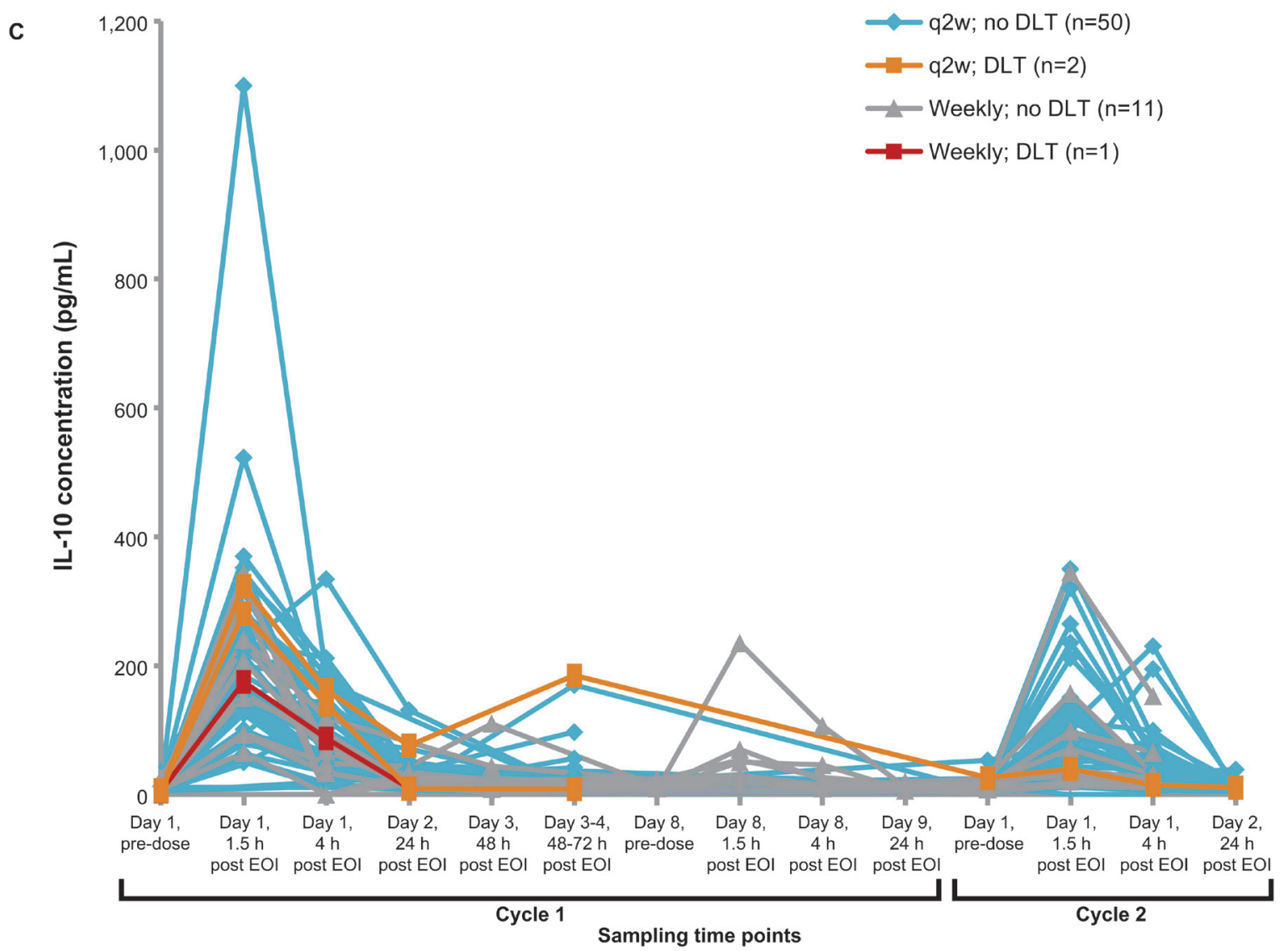

D

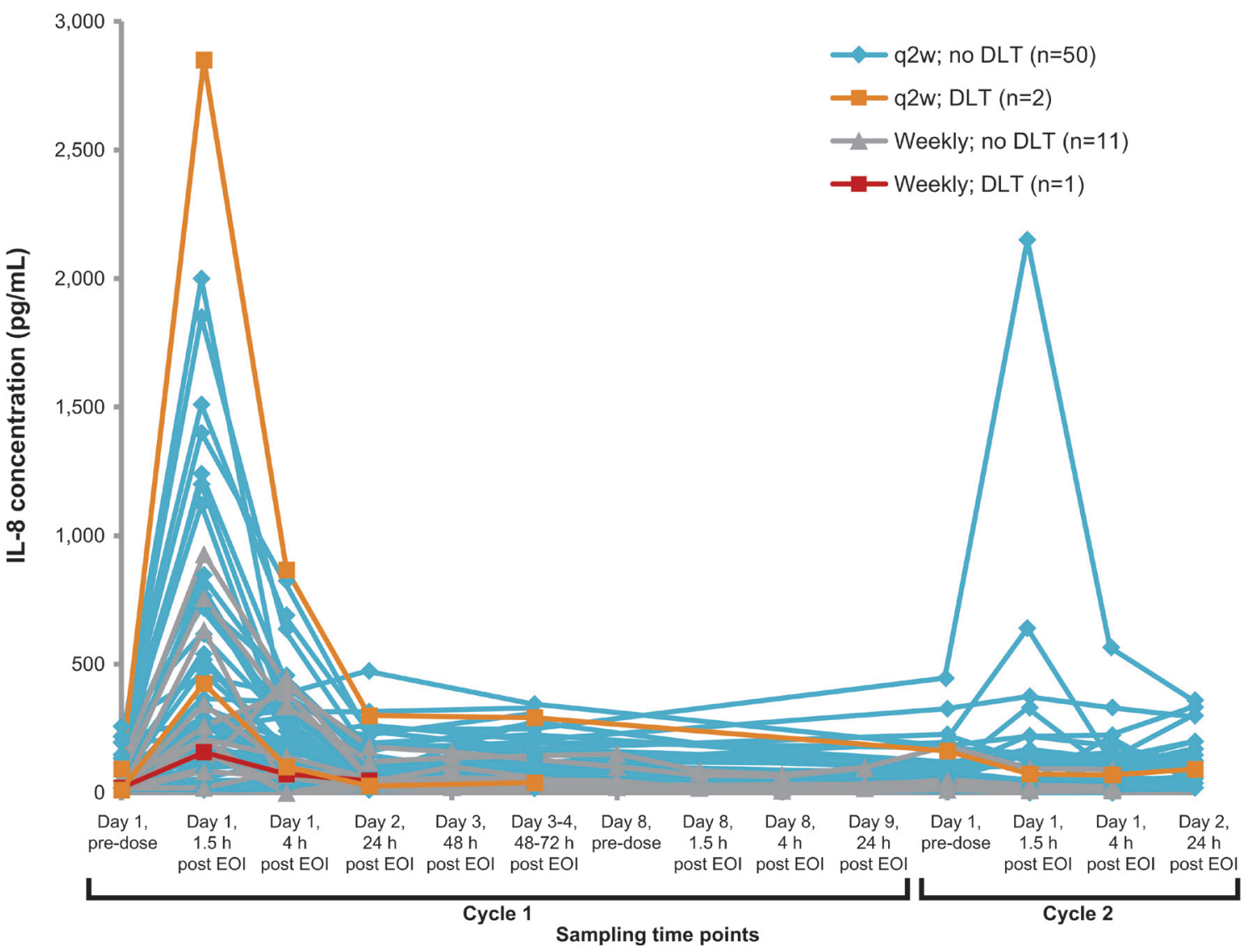


E

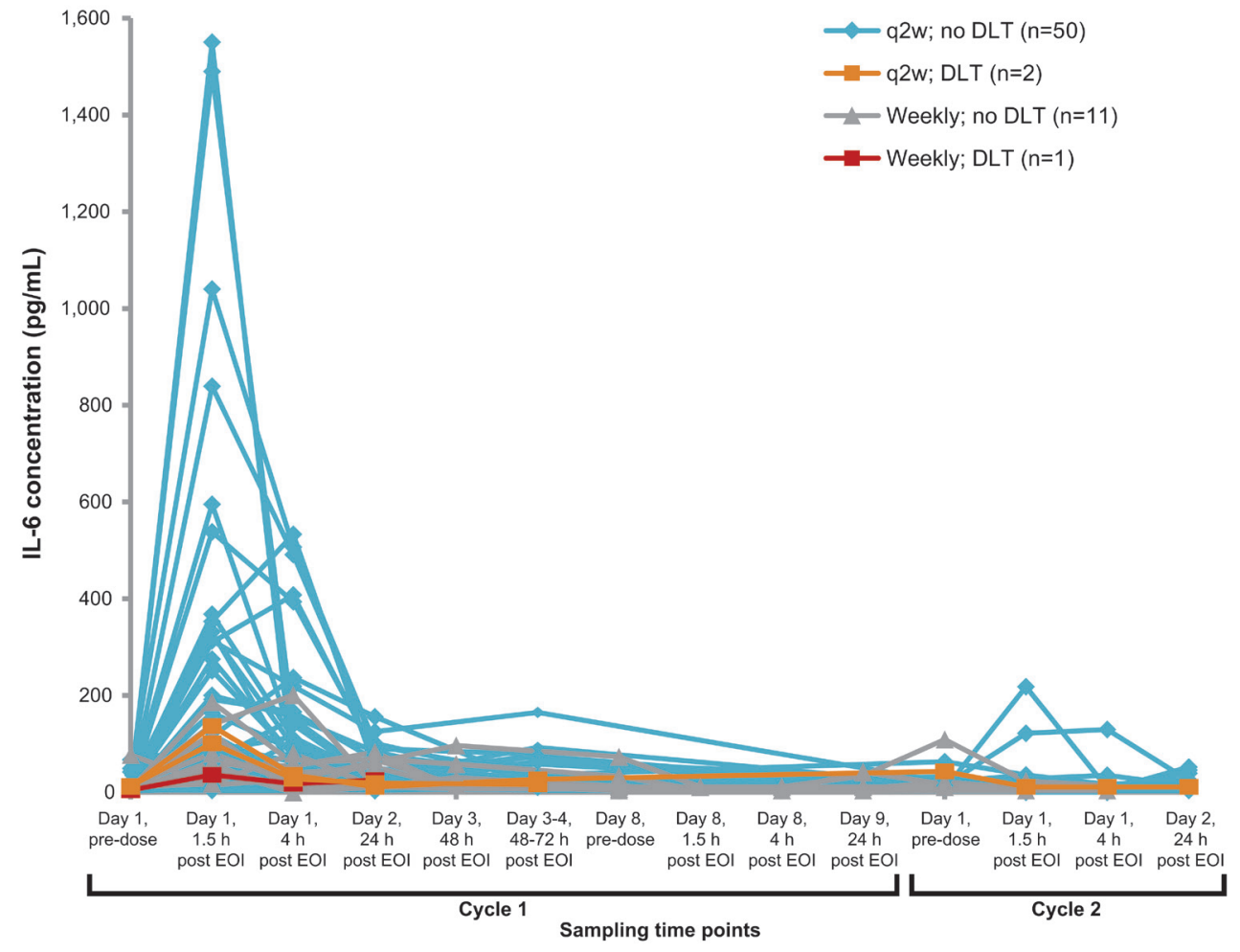

$\mathbf{F}$

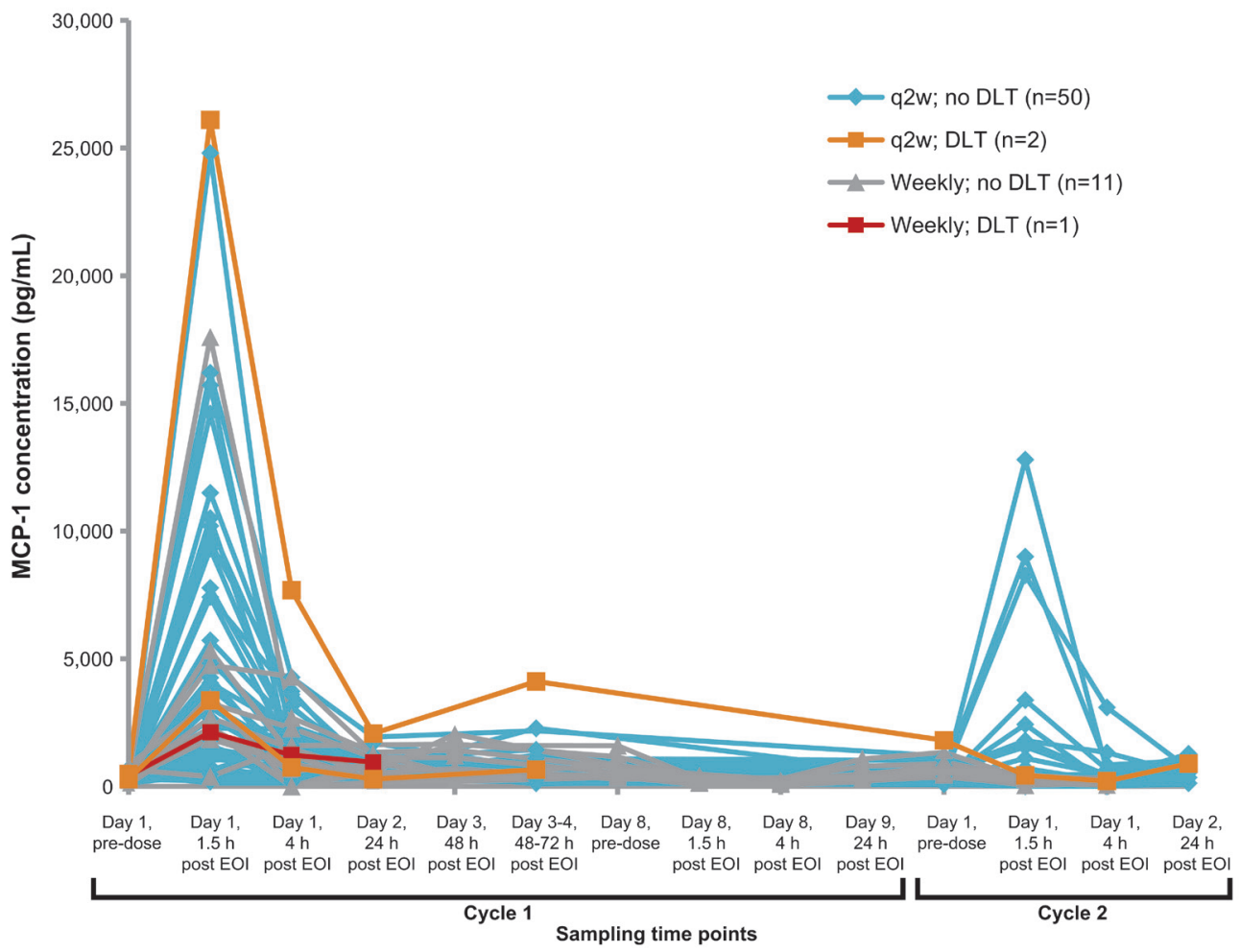

Figure 3: RG7356 induces a temporary reduction from baseline of CD14+ peripheral blood monocytes after first infusion (A), does not seem to have an effect on macrophage tumor infiltration (B), and generates a temporary release in cytokines. The latter seems to be independent of dose and/or dose-schedules (C-F). Dose-limiting toxicities (DLTs) occurred in 3 patients during the study: grade 3 febrile neutropenia on study day 18 and 2 cases of headache on study days 4 and 8 (C-F). Abbreviations: C (cycle); D (day); EOI (end of infusion); IL (interleukin); MCP-1 (monocyte chemoattractant protein-1); q2w (biweekly). A. Plot of mean changes from baseline of percent of $\mathrm{CD} 14+$ ( \pm standard deviation) at RG7356 doses $\geq 300 \mathrm{mg}$ for the $\mathrm{q} 2 \mathrm{w}$ schedule. B. Waterfall plot of percent change in CD68+ macrophages. C.-F. Individual cytokine profiles. 


\section{DISCUSSION}

This first-in-human phase I clinical trial with RG7356, a mAb targeted to the constant region of CD44, showed an acceptable safety profile in patients with advanced, CD44-expressing solid tumors. The study was terminated early due to no evidence of a clinical and/or pharmacodynamic (PD) dose-response relationship with RG7356, but not due to safety concerns. Consequently, the optimal biological dose schedule was not achieved. Headache and pyrexia were the most common AEs, the majority of which was related to IRRs most frequently occurring during the first infusion cycle. Two cases of grade 3 headache events occurred at the highest doses. Prior preclinical analysis had shown some accumulation of mononuclear cells in the meninges of cytomologous monkeys with RG7356 treatment (data on file) and aseptic meningitis occurred in 2 patients with acute myeloid leukemia (AML) treated with RG7356 (Vey et al, Phase I clinical study of RG7356, an anti-CD44 humanized antibody, in patients with relapsed/refractory acute myeloid leukemia; submitted to Oncotarget), possibly due to an inflammatory response in the meninges. Exploratory analyses showed no relationship between drug exposure, infusion-related cytokine release, and other AEs. Additionally, no accumulation of ${ }^{89} \mathrm{Zr} \mathrm{RG7356}$ to the meninges has been observed.

Bivatuzumab-mertansine, an antibody against CD44v6 linked to the anti-tubulin agent mertansine, was previously associated with significant skin toxicity, including a case of lethal epidermal necrolysis [6]. The efficient targeting of mertansine, which is highly toxic to skin, was most likely responsible for this toxicity. Despite abundant expression of CD44 in skin tissue of patients included in the present study (data not shown), RG7356 appeared safe and associated AEs were predominantly grade 1.

Clinical efficacy of RG7356 was modest with SD observed at 8 weeks in $21 \%$ of patients. Analysis of potential biomarkers showed reduction of $\mathrm{CD} 14+$ monocytes in peripheral blood suggesting a PD effect of RG7356; one of the proposed modes of action is to trigger direct antitumor effects by activating $\mathrm{CD} 68^{+}$macrophages via $\mathrm{Fc} / \mathrm{FcgR}$ interaction to phagocytose $\mathrm{CD} 44$-positive tumor cells. Reduction of circulating $\mathrm{CD} 14^{+}$monocytes might anticipate a migration and subsequent differentiation of monocytes into tumor tissue. However, no significant increase in $\mathrm{CD}^{+} 8^{+}$macrophages in tumor tissue was observed under RG7356 treatment.
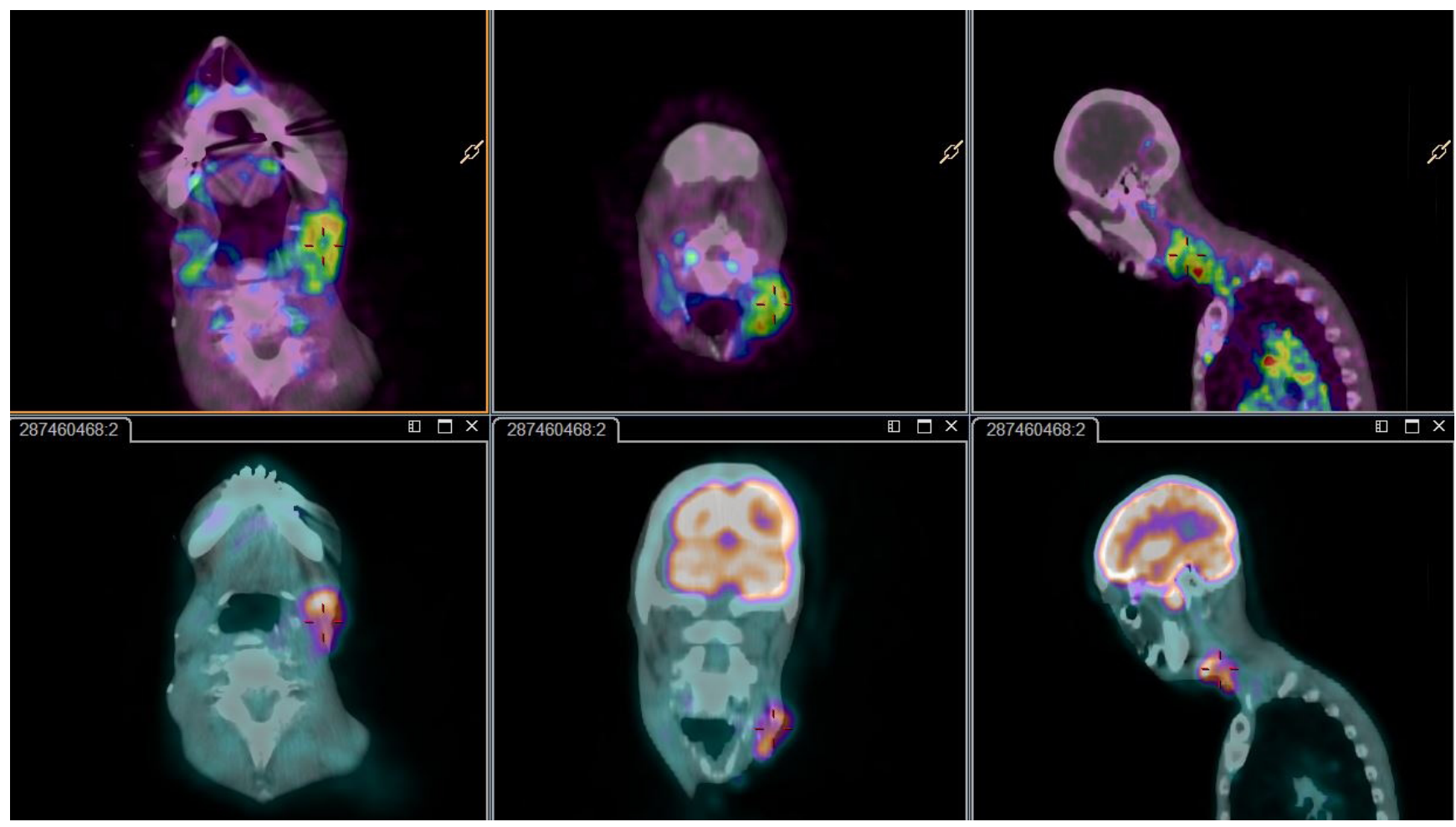

Figure 4: ${ }^{89} \mathrm{Zr}$-RG7356 uptake in tumor lesions. Representative images of lymph node metastases in left upper neck of a patient with advanced CD44-positive head and neck cancer. Upper row: ${ }^{89} \mathrm{Zr}$-RG7356 PET images acquired 5 days post injection. From left to right: axial, coronal and sagittal slices $(8 \mathrm{~mm})$ PET images fused with low-dose CT. Enhanced tracer uptake in malignant lymph nodes is shown (indicated by red center cross, $\mathrm{SUV}_{\max }$ 3.9). Lower row: ${ }^{18} \mathrm{~F}-\mathrm{FDG}$ PET images fused with low-dose CT (similar orientation as ${ }^{89} \mathrm{Zr}$-PET; $\mathrm{SUV}_{\max }$ 7.8). Note that spatial distribution of ${ }^{18} \mathrm{~F}$-FDG and ${ }^{89} \mathrm{Zr}$-RG7356 within the lesion is similar with central hypoactivity corresponding to necrosis. 
Plasma half-life was shorter than expected and, although qw dosing doubled RG7356 exposure, there was no improvement in antitumor activity. Deamidation of asparaginases in the complementarity determining region of intact antibody in plasma was demonstrated, whereby RG7356 is converted to a binding-impaired molecule that remains in circulation (data not shown). Thus, antibody levels decreased rapidly, with the remaining antibody inactivated, such that tumor exposure to intact RG7356 might have been too short-lived to procure clinical efficacy. Alternatively, patient heterogeneity in CD44s and CD44v expression may explain the observed activity. Four of 9 patients with tumors expressing predominantly CD44s showed some tumor shrinkage (1\% to $22 \%$ decrease), whereas none was observed in tumors predominantly expressing CD44v. Inhibition of the CD44s-HA interaction may be important for RG7356 clinical activity, as also demonstrated in preclinical studies [4].

We incorporated an exploratory immuno-PET analysis to assess biodistribution of ${ }^{89} \mathrm{Zr}$-RG7356. PET imaging using therapeutic agents as tracers has been developed in preclinical models and can potentially be used in early drug development to confirm expression of drug target in tumor sites and assess whole body biodistribution over time. These findings can help optimize dosage for better tumor targeting and prediction of response and understanding of side effects $[9,10]$. Preclinical evaluation previously demonstrated specific uptake of ${ }^{89} \mathrm{Zr}-\mathrm{RG} 7356$ comparable with that observed in our study [11]. Additionally, we observed significant accumulation of ${ }^{89} \mathrm{Zr}$-RG7356 in the liver, another "sink" organ potentially influencing drug availability. Unlike previous PET-imaging with novel-labeled mAbs to detect residual tumor lesions [12] or predict radioimmunotherapy dose exposure [13], this is one of the first phase I trials to our knowledge incorporating immunoPET to support early development of a novel compound by describing its biodistribution and tumor targeting at different doses. Tumor targeting of ${ }^{89} \mathrm{Zr}-\mathrm{RG} 7356$ at doses $\geq 200 \mathrm{mg}$ suggests that the disappointing activity was unrelated to drug delivery to the tumor. Alternatively, binding of RG7356 alone might not be sufficient to achieve antitumor activity, with preclinical data revealing that only 1 of 2 CD44-positive xenografts respond to RG7356 [11, 14]. Combination regimens may be needed to overcome potential drug resistance or tumor escape that may limit the efficacy of RG7356 as monotherapy.

In conclusion, in a heavily pretreated group of patients with metastatic and/or locally advanced CD44expressing solid tumors, RG7356 was well tolerated. The MTD was determined at $1,500 \mathrm{mg}$ in the $\mathrm{q} 2 \mathrm{w}$ regimen, but not defined in the qw regimen owing to early study termination for reasons unrelated to safety. Clinical efficacy was modest, with a best response of SD. The data support the use of immuno-PET in early clinical development, with proof-of-concept demonstrated using ${ }^{89} \mathrm{Zr}-\mathrm{RG} 7356$ PET. Tumor targeting from doses $\geq 200 \mathrm{mg}$ warrants further investigation of RG7356, perhaps in combination regimens.

\section{MATERIALS AND METHODS}

\section{Patient selection}

Detailed inclusion/exclusion criteria are provided in the Supplemental Material (online only). Briefly, patients with histologically confirmed metastatic and/or locally advanced malignant, CD44-expressing solid tumors not amenable to standard therapy were included. During the trial, it became apparent that CD44 isoform expression levels vary significantly among patients. Preclinical evidence also suggests that RG7356 preferentially interferes with binding of the CD44s isoform to HA [4]; thus, CD44s could potentially serve as a biomarker for prediction of response. Therefore, in the qw cohort, patients with tumors that express predominantly CD44s, including breast cancer, melanoma, renal and lung cancer, were preferentially included. All patients gave informed consent prior to any study procedure.

\section{Study design}

This first-in-human, open-label, multicenter, phase I, two-arm, dose-escalation, and imaging study (ClinicalTrials.gov Identifier NCT01358903) was approved by medical ethics committees of 6 participating centers in France, The Netherlands, and the United States and performed in accordance with the Declaration of Helsinki. A safety study management team of participating investigators and the study sponsor met every other week to review the data and agree on dose escalation and risk mitigation plans. Patients in Arm A received RG7356 in an escalating " $3+3$ " design from 100 up to $2,250 \mathrm{mg}$ q $2 \mathrm{w}$ or 675 or $1,350 \mathrm{mg}$ qw. In an exploratory imaging substudy, patients in Arm B received ${ }^{89} \mathrm{Zr}$-labeled RG7356. After Arm B completion, patients continued treatment with the highest Arm A dose that was cleared for DLT at that time point, and were evaluated per the Arm A assessment schedule.

Primary objectives were to describe safety and PK profiles of escalating RG7356 doses and to establish the MTD. DLT and MTD definitions are provided in the Supplemental Material (online only). Secondary objectives comprised describing antitumor activity (standard RECIST criteria, version 1.1) and determining the recommended RG7356 dose schedule for an extension cohort. Exploratory objectives included evaluating PD effects of RG7356 on blood, tumor, and skin samples. Additionally, 
DCE-MRI and FDG-PET were investigated. PET using ${ }^{89} \mathrm{Zr}-\mathrm{RG} 7356$ evaluated the in vivo biodistribution of ${ }^{89} \mathrm{Zr}$ RG7356.

\section{Treatment}

Arm A starting dose of $100 \mathrm{mg}$ was chosen based on the predicted threshold concentration required for tumor stasis and dose-escalation in increments $\leq 100 \%$ until clinically significant toxicity (two Grade 2 or one Grade $\geq 3$ toxicity, or drug-related toxicity deemed significant by the investigator) was observed, at which time the maximum-allowed increase would not exceed $50 \%$. Doses were increased up to 2,250 mg. Patients were enrolled into 8 dose cohorts to receive RG7356 q2w, and into 2 dose cohorts (675 and 1,350 $\mathrm{mg}$ ) for the qw regimen (Supplemental Material, online only). Patients continued treatment in the same cohort until disease progression, unacceptable toxicity, or withdrawal. In Arm B, $37 \mathrm{MBq}$ of ${ }^{89} \mathrm{Zr}$-label containing $1 \mathrm{mg}$ of RG7356 was administered as a $20 \mathrm{~mL}$ bolus after a predetermined amount of cold RG7356.

\section{Safety}

Patients were monitored for AEs for 2 hours post infusion at each visit. DLTs were assessed over a safetymonitoring period of 28 days and as necessary throughout the study. Routine hematology and biochemistry laboratory assessments were performed before and after treatment on days 1 and 8 of each cycle.

\section{Pharmacokinetic analysis}

Blood sampling was performed on each treatment day before and after infusion, and on days 2, 3, and 8 after the first treatment cycle. Estimation of PK parameters was performed using standard noncompartmental (model independent) methods. Actual sampling time was used to calculate PK parameters. PK analysis was performed using Phoenix $^{\circledR}$ WinNonlin ${ }^{\circledR}$ version 6.2.

\section{Biomarker analysis}

Blood samples were taken during cycles 1, 2, and 4 for immunophenotyping of circulating immune cells and for cytokine analysis (Supplemental Material, online only). To assess a potential alteration of macrophages in the tumor due to RG7356, paired tumor tissue samples collected at baseline and cycle 3 day 1 were analyzed for $\mathrm{CD}^{+} 8^{+}$macrophages via IHC (details of these procedures can be found in the Supplemental Material, online only). Tumor biopsies were collected to assess CD44 expression at baseline, on day 1 cycle 3 , and optionally at tumor progression (Supplemental Material, online only).

\section{Imaging}

To monitor tumor interstitial fluid pressure, DCEMRI assessments were performed before and $48 \pm 12$ hours after end of infusion in cycle 1 and up to 12 hours after end of infusion in cycle 3 for doses $>400 \mathrm{mg}$ for patients with at least 1 tumor lesion $\geq 1 \mathrm{~cm}$ outside the thoracic cavity, without metal implants or impaired renal function. Tumor metabolism changes were studied using FDG-PET according to European Association of Nuclear Medicine guidelines [15] before start and before the second and fourth treatment cycles. Whole-body PET with ${ }^{89} \mathrm{Zr}$-labeled RG7356 (Supplemental Material, online only) was performed in a subgroup of patients on days 1,2 , and 5 post injection to evaluate tumor targeting and organ biodistribution.

\section{ACKNOWLEDGMENTS}

This phase I clinical study was sponsored by F. Hoffmann-La Roche Ltd. The authors would like to thank Marc C. Huisman, Otto S. Hoekstra, Emma R. Mulder, Ronald Boellaard, and Danielle J. Vugts from the Department of Nuclear Medicine for their support with the ${ }^{89} \mathrm{Zr}$ PET-imaging conducted in this study, the site and sponsor study management teams, and the patients who agreed to participate in the study. Under the direction of the authors, editorial assistance was provided by Samantha Taylor, $\mathrm{PhD}$, of Envision Scientific Solutions, and funded by F. Hoffmann-La Roche Ltd.

\section{CONFLICTS OF INTEREST}

CWMVDHVO: No conflicts to disclose, CG: No conflicts to disclose, $\mathrm{CVH}$ : No conflicts to disclose, $\mathrm{AC}$ : No conflicts to disclose, DM: No conflicts to disclose, HMWV: Research funding: F. Hoffmann La-Roche, WTAVDG: Advisory role: Bayer; Research funding: GlaxoSmithKline, CLT: No conflicts to disclose, TKN: Holds stocks of F. Hoffmann La-Roche, RC, DR, SW, MAC, FH, MB, ACW, TKN, EG, and VM are or have been employees of Roche.

\section{GRANT SUPPORT}

The phase I clinical study (ClinicalTrials.gov Identifier NCT01358903) was sponsored by F. HoffmannLa Roche Ltd, Basel, Switzerland. 


\section{REFERENCES}

1. Orian-Rousseau V. CD44, a therapeutic target for metastasising tumours. Eur J Cancer. 2010; 46: 1271-1277. doi: 10.1016/j.ejca.2010.02.024

2. Zöller M. CD44: can a cancer-initiating cell profit from an abundantly expressed molecule? Nat Rev Cancer. 2011; 11: 254-267. doi: 10.1038/nrc3023

3. Naor D, Nedvetzki S, Golan I, Melnik L, Faitelson Y. CD44 in cancer. Crit Rev Clin Lab Sci. 2002; 39: 527-579. doi: $10.1080 / 10408360290795574$

4. Birzele F, Voss E, Nopora A, Honold K, Heil F, Lohmann S, Verheul HM, Le Tourneau C, Delord JP, van Herpen CM, Mahalingam D, Coveler AL, Meresse Naegelen V, et al. CD44 isoform status predicts response to treatment with anti-CD44 antibody in cancer patients. Clin Cancer Res. 2015; 21: 2753-2762. doi: 10.1158/1078-0432.CCR-142141

5. Farghaly SA. Cancer stem cells (Csc's): emerging concept and strategy for targeting progression of epithelial ovarian cancer. Enliven: Challenges Cancer Detect Ther. 2014; 1: e001.

6. Tijink BM, Buter J, de Bree R, Giaccone G, Lang MS, Staab A, Leemans CR, van Dongen GA. A phase I dose escalation study with anti-CD44v6 bivatuzumab mertansine in patients with incurable squamous cell carcinoma of the head and neck or esophagus. Clin Cancer Res. 2006; 12: 6064-6072. doi: 10.1158/1078-0432.CCR-06-0910

7. Sauter A, Kloft C, Gronau S, Bogeschdorfer F, Erhardt T, Golze W, Schroen C, Staab A, Riechelmann H, Hoermann K. Pharmacokinetics, immunogenicity and safety of bivatuzumab mertansine, a novel CD44v6targeting immunoconjugate, in patients with squamous cell carcinoma of the head and neck. Int J Oncol. 2007; 30: 927 935.

8. Rupp U, Schoendorf-Holland E, Eichbaum M, Schuetz F, Lauschner I, Schmidt P, Staab A, Hanft G, Huober J, Sinn HP, Sohn C, Schneeweiss A. Safety and pharmacokinetics of bivatuzumab mertansine in patients with CD44v6positive metastatic breast cancer: final results of a phase I study. Anticancer Drugs. 2007; 18: 477-485. doi: 10.1097/ CAD.0b013e32801403f4

9. van Dongen GA, Huisman MC, Boellaard R, Hendrikse $\mathrm{N}$, Windhorst AD, Visser GW, Molthoff CF, Vugts DJ. 89Zr-immuno-PET for imaging of long circulating drugs and disease targets: why, how and when to be applied? Q J Nucl Med Mol Imaging. 2015; 59: 18-38.
10. Mammatas LH, Verheul HM, Hendrikse NH, Yaqub M, Lammertsma AA, Menke-van der Houven van Oordt CW. Molecular imaging of targeted therapies with positron emission tomography: the visualization of personalized cancer care. Cell Oncol (Dordr). 2015; 38: 49-64. doi: 10.1007/s13402-014-0194-4

11. Vugts DJ, Heuveling DA, Stigter-van Walsum M, Weigand S, Bergstrom M, van Dongen GA, Nayak TK. Preclinical evaluation of ${ }^{89} \mathrm{Zr}$-labeled anti-CD44 monoclonal antibody RG7356 in mice and cynomolgus monkeys: prelude to Phase 1 clinical studies. MAbs. 2014; 6: 567-575. doi: 10.4161/mabs. 27415

12. Börjesson PK, Jauw YW, Boellaard R, de Bree R, Comans EF, Roos JC, Castelijns JA, Vosjan MJ, Kummer JA, Leemans CR, Lammertsma AA, van Dongen GA. Performance of immuno-positron emission tomography with zirconium-89-labeled chimeric monoclonal antibody U36 in the detection of lymph node metastases in head and neck cancer patients. Clin Cancer Res. 2006; 12: 21332140. doi: 10.1158/1078-0432.CCR-05-2137

13. Börjesson PK, Jauw YW, de Bree R, Roos JC, Castelijns JA, Leemans CR, van Dongen GA, Boellaard R. Radiation dosimetry of ${ }^{89} \mathrm{Zr}$-labeled chimeric monoclonal antibody U36 as used for immuno-PET in head and neck cancer patients. J Nucl Med. 2009; 50: 1828-1836. doi: 10.2967/ jnumed.109.065862

14. Weigand S, Herting F, Maisel D, Nopora A, Voss E, Schaab C, Klammer M, Tebbe A. Global quantitative phosphoproteome analysis of human tumor xenografts treated with a CD44 antagonist. Cancer Res. 2012; 72: 4329-4339. doi: 10.1158/0008-5472.CAN-12-0136

15. Boellaard R, O’Doherty MJ, Weber WA, Mottaghy FM, Lonsdale MN, Stroobants SG, Oyen WJ, Kotzerke J, Hoekstra OS, Pruim J, Marsden PK, Tatsch K, Hoekstra CJ, et al. FDG PET and PET/CT: EANM procedure guidelines for tumour PET imaging: version 1.0. Eur J Nucl Med Mol Imaging. 2010; 37: 181-200. doi: 10.1007/s00259-009$1297-4$ 